\title{
Ergonomic Workplace Evaluation for Assessing Occupational Risks in Multistage Pump Assembly
}

\author{
Nishanth R. \\ Dept. of Production \\ Engineering, \\ PSG College of \\ Technology, \\ Coimbatore, \\ India
}

\author{
Muthukumar M. V. \\ Dept. of Production \\ Engineering, \\ PSG College of \\ Technology, \\ Coimbatore, \\ India
}

\author{
Arivanantham A. \\ Dept. of Production \\ Engineering, \\ PSG College of \\ Technology, \\ Coimbatore,
}

India

\author{
P. Ashok \\ Assistant Professor \\ Department of Production Engineering \\ PSG College of Technology \\ Coimbatore 641004, Tamil Nadu, India
}

\author{
G. Madhan Mohan, PhD \\ Assistant professor (Senior Grade) \\ Department of Production Engineering \\ PSG College of Technology \\ Coimbatore 641004, Tamil Nadu, India
}

\begin{abstract}
This paper focuses on reducing the occupational risks while assembling a multistage pump. A sample of 10 employees who assemble the multistage pump from an Indian semiautomatic pump manufacturing industry was studied. Awkward postures manifested in these tasks cause strain in the employee's body which lead to fatigue, injuries and musculoskeletal disorders. These tasks were evaluated on the basis of standards set by the National Institute for Occupational Safety and Health (NIOSH). This evaluation adopts posture assessment using Rapid Upper Limb Assessment (RULA) and bio-mechanical approach to examine the tasks. Engineering interventions were then developed and evaluated in ergonomics laboratory to document the reduction of risks. The ergonomic tool introduced in this study has the potential to considerably reduce the occupational risk in pump assembly.
\end{abstract}

\section{Keywords}

Occupational risks, RULA, Bio-mechanics, Pump Industry

\section{INTRODUCTION}

Workplaces are a major part of the manufacturing industry that is needed to accomplish various types of job. The quality of the design of workstation in terms of the requirement of the worker has an important effect on ease with which the activity is accomplished. Improper workstation design can be an important factor responsible for the development of various work related musculoskeletal disorders (WMSD). The WMSD pose occupational risks to the employees which reduces the productivity of a manufacturing company and also affect the health of employees has been demonstrated by Nicolas [7]. Further the studies conducted by Battini, Faccio, Persona and Sgarbossa [2] also reveal the implication of efficient ergonomics in workstation design shows better interaction between man-machine systems. Study regarding employee performance and comfort in assembly task has been done and the output workstation may function with less efficiency, if anthropometry data mismatches with workstation design.

The ergonomics analysis is performed in the virtual environment using CATIA software as discussed by karmakar, Sanjog and Thaneswer [14]. Due to the awkward posture the workers face many health issues like shoulder pain, neck pain and back pain. The lumbar spine may experience significant forces during occupational tasks due to

The force of gravity acting on the upper body when bending the trunk forward, so need to restrict the load on the spine within The National Institute for Occupational Safety and Health (NIOSH) recommended spine limit.

Granata, Marras and Davis [6] attempted to determine ergonomic acceptable limits according to the NIOSH method. NIOSH limit proved useful for identifying certain lifting jobs that posed a risk to the musculoskeletal system for developing lifting related low back pain.

The analysis of work stress during process among Indian workers has been carried out in an Indian semiautomatic pump manufacturing industry. Ergonomic study on manual component insertion line in Stator pump which has high assembly time has been done using method of questionnaire, direct interview and archived data as discussed by Sangeeta, Prakash and Debkumar [10].

The objective of this study is to analyze the working posture of workers engaged in stator assembly by applying different postural analysis tools and to identify the various risk factors associate with WMSD. Associations between the risk factors and the musculoskeletal complaints have been well categorized by Nirathi and Kari [8], Low back pain is one of the most prevalent WMSD.

\section{METHODOLOGY}

This study was conducted on assembly workstation in a stator assembly section. Different parts of pump are assembled by manual process. Assembly process consists of parts of different size and weights; Inserted into the pump casing. There are ten employees who are working in this workstation. Their anthropometric measurements are carried out by direct measurements.

The main focus is to find out the complex task of assembly which leads to more time consumption, causing fatigue and reduces occupational risk among workers. Static ergonomic posture analysis is done by capturing pictures of assembly process using high definition camera. The worker body postures and the movement of other body members are 
captured and analyzed using RULA posture analysis method and verified by biomechanical approach according to the biomechanical guideline for occupational low back disorder prevention [3]

\subsection{Existing Workstation}

The task performed by the employee is the assembly of stator pump parts using manual insertion process.

In order to assemble the parts inside the pump casing, the employee has to bend his neck and trunk as shown in Fig 1. The process consists of repetitive tasks which seem to be hectic where the employee has to bend forward for every component assembly inside the pump casing. Employees are Indian male working in stator assembly section and their anthropometry data are mentioned below.

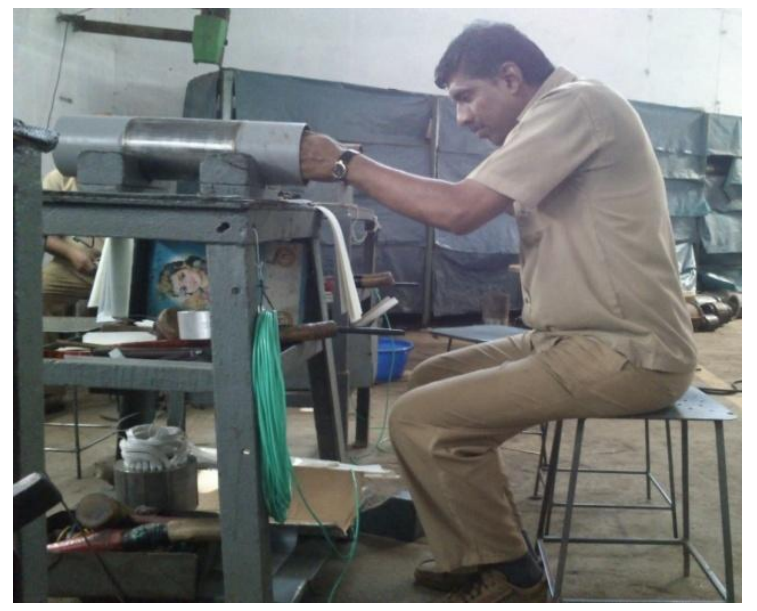

Fig 1: Existing Posture

Table: 1 Anthropometry Data of Employees working in stator assembly

\begin{tabular}{|l|c|c|}
\hline \multicolumn{1}{|c|}{ Body Dimension } & $\begin{array}{c}\mathbf{5 0}^{\text {th }} \\
\text { percentile, } \\
\mathbf{c m}\end{array}$ & $\begin{array}{c}\text { Range, cm min- } \\
\text { max }\end{array}$ \\
\hline Statue Height & 172.6 & $157.0-181.0$ \\
\hline Eye Height & 161.1 & $144.0-168.0$ \\
\hline Shoulder height & 145.0 & $130.0-150.0$ \\
\hline Elbow Height & 109.0 & $96.0-115.0$ \\
\hline Knuckle Height & 75.3 & $70.2-80.4$ \\
\hline Sitting Height Erect & 91.3 & $85.1-97.5$ \\
\hline Eye Height Sitting & 79.3 & $73.4-85.2$ \\
\hline Elbow Rest Height & 27.8 & $25.4-30.2$ \\
\hline $\begin{array}{l}\text { Thigh Clearance } \\
\text { Height }\end{array}$ & 12.9 & $11.0-15.2$ \\
\hline Knee Height & 56.4 & $52.0-60.0$ \\
\hline Buttock-Knee Length & 57.7 & $55.0-60.0$ \\
\hline
\end{tabular}

\begin{tabular}{|l|c|c|}
\hline Popliteal Height & 42.2 & $40.0-44.0$ \\
\hline Chest Depth & 21.2 & $19.0-23.0$ \\
\hline $\begin{array}{l}\text { Elbow to Elbow } \\
\text { Breadth }\end{array}$ & 46.5 & $41.0-51.0$ \\
\hline Hip Breadth & 32.0 & $27.5-36.0$ \\
\hline Weight & 75.9 & $60.0-85.0$ \\
\hline
\end{tabular}

This Anthropometry data are used for building manikin in CATIA software and bio-mechanics as discussed by karmakar, Sanjog and Thaneswer [14]. Those results are further used to design the work holding adjustable fixture.

\subsection{Stator Assembly}

The employees work on the stator assembly which consists of $3.5 \mathrm{HP}$ to $25 \mathrm{HP}$ pump assembly. This is placed on the VBlock fixture, different sizes of stator pump casing can be placed on the V-block fixture, but it is non-adjustable.

Time taken to assemble for $3.5 \mathrm{Hp}$ to $25 \mathrm{Hp}$ pump is about 0.30 to 12 hours per day. Total $24,36,48,52$ slot's vary according to Pump HP and every slot needs to be fixed with insulation sheet, Bamboo stick and copper wire inside it (copper wire diameter vary from 0.9 to $1.9 \mathrm{~mm}$ and length vary from 100 to $500 \mathrm{~m}$ ). The stator pump which is placed on the table measures $0.93 \times 0.30 \times 0.92$ meters and size of the chair where the employee is sitting is $0.36 \times 0.38 \times 0.51$ meters. The pump casing is placed on the V-Block fixture at the height of 0.96 meters.

\subsection{Direct Method}

When employees were interviewed for obtaining information regarding awkward postures and complex task, various illnesses were informed by these workers including neck pain, back pain, and shoulder pain leading to reduced efficiency of workers and in severe cases long duration pains.

Analysis of these factors is done by capturing pictures using high definition camera and root causes of these illness are found out.

The manikin is developed using CATIA software from Fig 1, and angles of the body segments are measured using AUTOCAD software.

\subsection{Binocular Visual Field}

Employees are not able to clearly view the inside component of the pump casing as shown in Fig 2 because of the position in which the pump casing is placed on the table, the Visual Fields with Head and Eye Movement is well demonstrated in Surface Vehicle Information Report Superseding [13]. The employee needs to bend frequently for assembling the component inside the pump casing.

\subsection{Ergonomic Risk Factors}

Ergonomic risk factors associated with upper extremity MSD score for neck trunk and leg is 5 and their RULA score is 5 based on Rapid Upper Limb Assessment (RULA) [9], it is concluded that the working posture is improper and needs to be modified. Employees are not able to maintain standard body postures and movement because of poor work place design. Hence, leading to fatigue like shoulder stress, back pain and neck pain reducing working efficiency. 


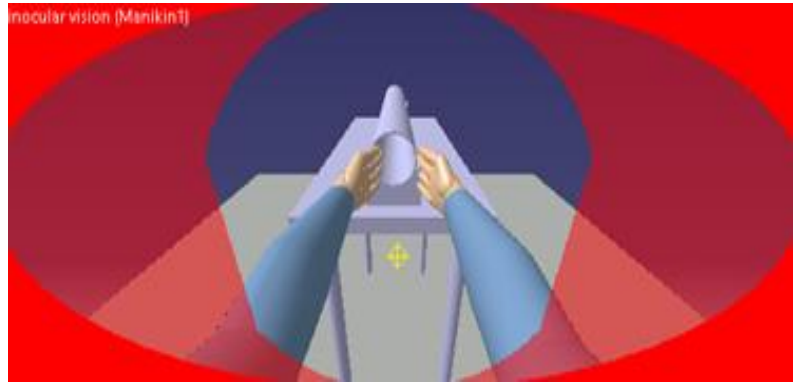

Fig 2: Binocular Vision of Manikin

\subsection{Design of Height Adjustable Fixture}

The designer has to analyze in what ways anthropometric mismatches might occur and then decide which anthropometric data might be able to solve the problem.

To overcome WMSD we have implemented a height adjustable fixture, in which different pump casing size can be place. Design of adjustable fixture was made on the basis of anthropometry data collected from the employees.

The employees do not have to bend their trunk and neck frequently to accommodate them to individual job while assembling in stator assembly section Body.

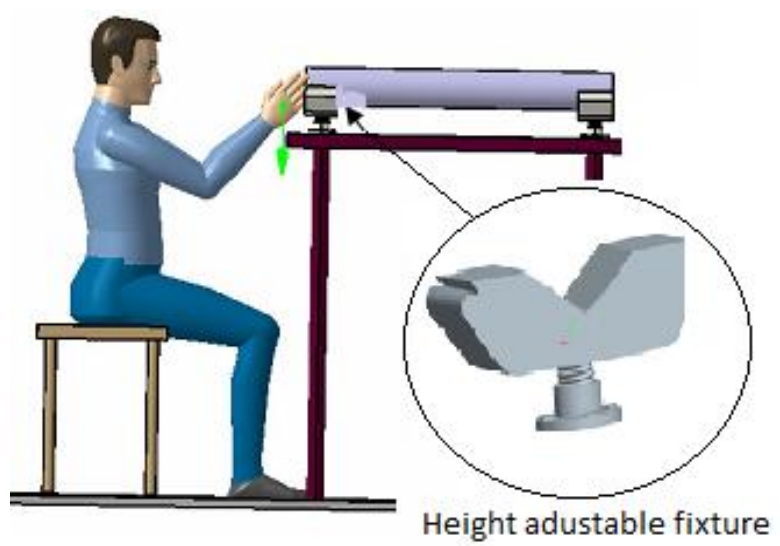

Fig 3: Revised Posture Development using CATIA

\subsection{Binocular Visual Field for Revised Posture}

Manikin is able to clearly see inside the pump casing with the help of height adjustable fixture as shown in Fig 4.

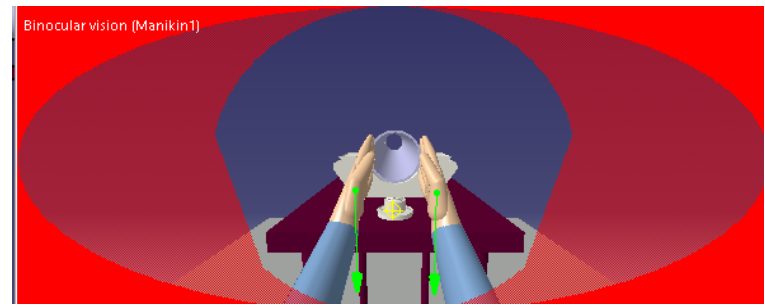

Fig 4: Binocular Vision of Manikin

\subsection{Ergonomic Risk Factors}

Ergonomic risk factors associated with upper extremity for the revised posture, MSD score for neck trunk and leg is 2 and their RULA score is 3.

This will help the worker to work with less, workload and maintain a good posture, which in turn reduces fatigue and maintain health of the worker.
A recommendation for worktable surface height should be $0.96-1.15$ meters, which will accommodate every individual in the work place which is designed from their anthropometry data.

\section{BIO-MECHANICAL APPROACH}

Biomechanics is the application of the principles of mechanics to the physical structure of human beings. The person pictured in Fig 1 is working in the upright position, the worktable is at a low height even though the work area is of the correct armreach length, so the thoracolumbar spine is inclined at an angle, $\theta=75^{\circ}$, explained by Phillips [4] and it helped in evaluating the Force and moments, we use the concept of free body diagram to solve the equilibrium equations

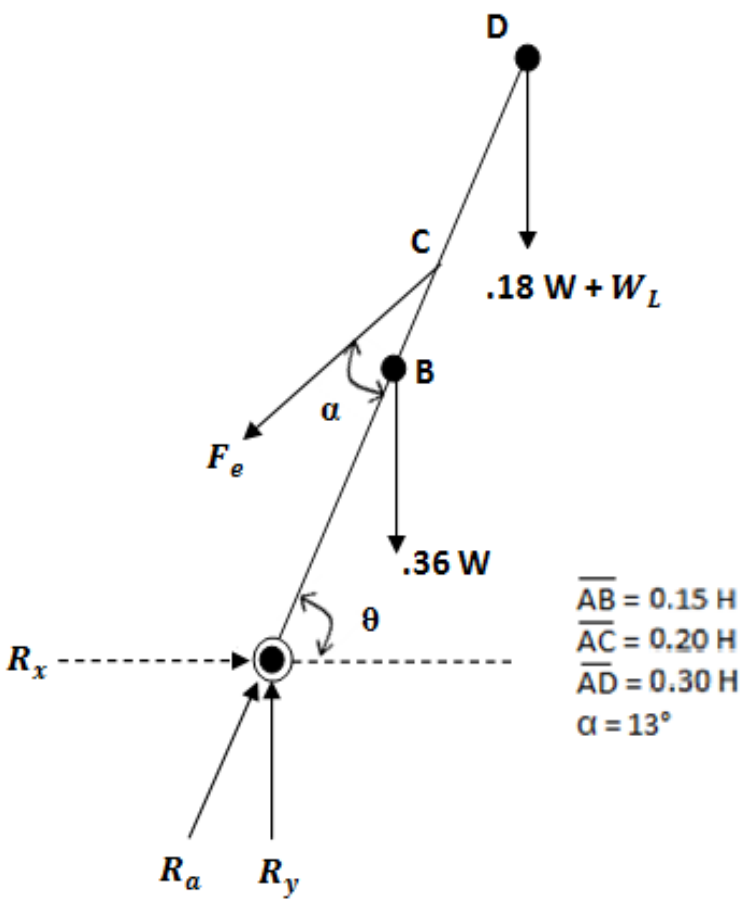

Fig 5: Free-body diagram of the thoraco-lumbar spine By using the force and moment equation,

$R_{a}$ - axial reaction force along the central axis of the spine

$\mathrm{F}_{\mathrm{e}}$ - The extersor muscle force

$\mathrm{W}_{\mathrm{B}}$ - Body weight $=75.90 \mathrm{Kg}$

$$
\begin{array}{ll}
\mathrm{R}_{\mathrm{a}} \times 1.13 \times \mathrm{W}_{\mathrm{B}} & =841.36 \mathrm{~N} \\
\mathrm{~F}_{\mathrm{e}}=0.624 \mathrm{XW}_{\mathrm{B}} & =464.61 \mathrm{~N}
\end{array}
$$

Poor workplace design, requiring the person to bend at the waist by an additional $10^{\circ}$, increases Lumbosacral axial forces by $65 \%$. The Fig 3, show the working posture in the upright position with a worktable at a correct height and a work area of correct arm reach length so that the thoracolumbar spine is at an angle, $\theta=85^{\circ}$.

$$
\begin{array}{ll}
\mathrm{R}_{\mathrm{a}} \times 0.741 \times \mathrm{W}_{\mathrm{B}} & =551.73 \mathrm{~N} \\
\mathrm{~F}_{\mathrm{e}}=0.208 \times \mathrm{W}_{\mathrm{B}} & =154.87 \mathrm{~N}
\end{array}
$$

In an upright position, only body weight forces are being experienced, the lumbosacral joint is subjected to an axial force of three-fourths of the body weight. 
The commonly used biomechanical measures include peak joint moment, peak compression force on the spine and peak shear force on the lumbar spine the most commonly adopted by many researches $[3,6,12]$. Therefore, the present work followed the same criteria to find out the compression limits for the L4/L5 Joints.

\subsection{L4-L5 region}

Using the CATIA biomechanics single action analysis the force on the L4-L5 compression force is calculated for Fig 3 and NIOSH (National Institute for Occupational Safety and Health) spine limits.

\begin{tabular}{|l|l|}
\hline Analysis & Value \\
\hline L4-L5 Moment (Nxm) & 18 \\
& \\
L4-L5 Compression (N) & 701 \\
Body Load Compression (N) & 408 \\
Axial Twist Compression (N) & 0 \\
Flex/Ext Compression (N) & 292 \\
& 48 Posterior \\
L4-L5 Joint Shear (N) & \\
Abdominal Force (N) & 0 \\
Abdominal Pressure (N_m2) & 0
\end{tabular}

Fig 6: Bio-mechanics single action analysis the force on the L4-L5

Among the recommendations proposed by various agencies, the National Institute of Occupational Safety and Health (NIOSH) Work Practices Guide [3, 6, 12, 13] has been more widely distributed and adopted. Many Countries either do not have a limit on weights for safe lifting/carrying and/or limits set Fig 7.
Compression Limits

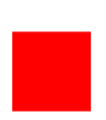

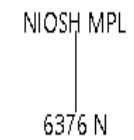

$6376 \mathrm{~N}$
Fig 7: NIOSH Spine limits

Based on the various design criteria, two limits are proposed. Action limit (AL) loads under this limit can be lifted by $99 \%$ of men and $75 \%$ of women, and maximum permissible limit (MPL) loads that can be sustained by only $25 \%$ of men and $1 \%$ of women. At the workplace, administrative controls and engineering controls (eg. mechanization) are required for weights between the action limit and maximum permissible limit.

The compression force Fig 6. Imposed on the spinal column, for a given task condition (weight, load size) are compared with the Fig 7 force tolerance limit of the spine (NIOSH), under consideration is within the acceptable range.

A type of Biomechanical model is presented, which provides a mean to quickly estimate the effect of the postures adopted by workers during industrial work, particularly in sitting postures. The Proposed model can predict the moments on joints, as well as the forces in erector spinae muscle and L4L5 spinal region.

\section{RESULT AND DISCUSSION}

This study was conducted on an assembly station in a stator assembly section. The section was facing problems of less efficiency in workers due to poor ergonomics and in some severe cases hazardous health issues were found. Here attempt has been made to identify fatigue causing factors which leads to reduced efficiency of workers hence less productivity of workstations.
To study and analyze factors causing less efficiency, RULA and biomechanical study techniques are used. The other sources of data are interview with workers, managers and archived documents. Ergonomically improved workplace layout helps in reduced stress on workers, elimination of repetitive tasks, cycle time reduction and hence increased productivity.

Hence from the RULA score and bio-mechanics force analysis, it is seen that the revised posture extersor muscle force is less than that of the existing posture and concludes that revised posture is ergonomic posture.

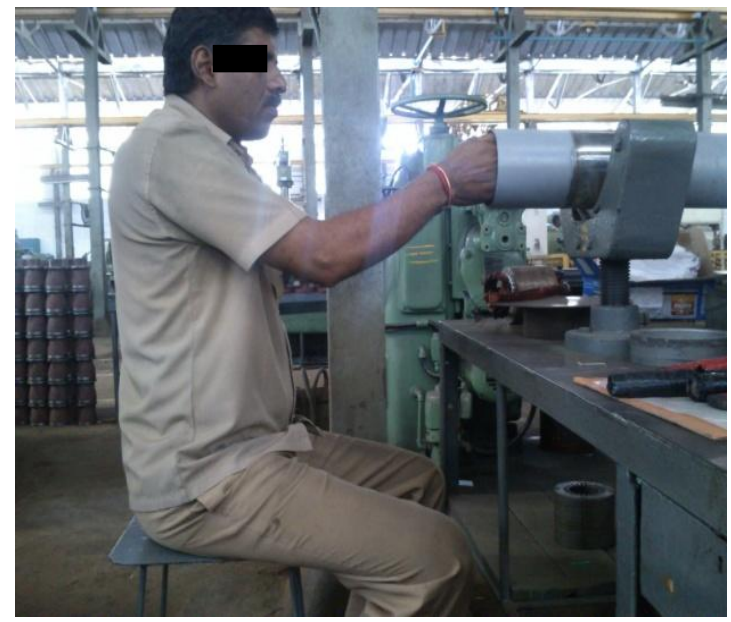

Fig 8: After implementation of height adjustable Fixture in their work place

Fig 8, After the implementation, the operators aren't facing much pain in the back and neck. They can see inside the pump casing clearly without adjusting themselves, Hence MSD risk factor is reduced.

\section{CONCLUSION}

The Posture assessment has been performed on the employees working in a stator assembly shop and the result has been compared using CATIA and Bio-mechanics analysis. A biomechanics analyse and RULA score indicated 'at risk' jobs have been performed on work activities in occupation groups. The model provides the severity of the posture towards MSDs, through the investigation of risk factors and recommendations for reducing risk have been provided with a vision to demonstrate compliance with the requirements of existing ergonomic legislation directed at improving working posture. Significant insights have been gained through using a methodology that combines assessment techniques to derive risk of musculoskeletal injury. The combination and crossreferencing of these risk indexes provided the information necessary to develop the prevention strategies recommended.

This study can be further improved by analysing psychosocial of the employee, Energy expenditure and Heart rate variability based on discussion made by Adams and Dolan [1], Dukie et al [5], Centers for Disease Control and Prevention [8].

It is the duty of the management of every company to provide comfortable working environment for employees and to support the well-being of workers.

\section{ACKNOWLEDGEMENTS}

Involvement of the staffs and management of PSG Industrial institute and PSG College of Technology, Coimbatore, India 
are well supported. Without their cooperation and participation, this study would not have been possible.

We are grateful to all workers for providing us valuable data.

\section{REFERENCES}

[1] Arja Uusitalo ., Terhi Mets ., Kaisu Martinmäki ., Saija Mauno ., Ulla Kinnunen and Heikki Rusko., 2011. Heart rate variability related to effort at work. Applied Ergonomics 42, 830-838.

[2] Battini.D., Faccio.M., Persona.A and Sgarbossa.F., 2011. New methodological framework to improve productivity and ergonomics in assembly system design. International Journal of Industrial Ergonomics 41, 30-42.

[3] Biomechanical guideline for occupational low back disorder prevention a field assessment and prevention guideline setup, January 2005. Occupational Safety and Health Council.

[4] Chandler Allen Phillips., 2000. Human Factor Engineering. $1^{\text {st }}$ edition, John Wiley $\&$ Sons.

[5] Danielle R., Bouchard and Francois Trudeau., 2007. Reliability of the assessment of the oxygen/heart rate relationship during a workday. Applied Ergonomics 38, 491-497.

[6] Granata.K. P., Marras.W.S .,Davis.K.G.,1999. Variation in spinal load and trunk dynamics during repeated lifting exertions. Clinical Biomechanics 14.

[7] Nicolas Vignais ., Markus Miezal ., Gabriele Bleser ., Katharina Mura ., Dominic Gorecky and Frédéric Marin., 2013. Innovative system for real-time ergonomic feedback in industrial manufacturing. Applied Ergonomics 44, 566-574.
[8] Nirathi Keerthi Govindu and Kari Babski-Reeves., 2014. Effects of personal, psychosocial and occupational factors on low back pain severity in workers. Available from www.elsevier.com/locate/ergon.

[9] Rapid Upper Limb Assessment (RULA) Ergonomics plus Available from: www.ergo-plus.com.

[10] Sangeeta Pandit., Prakash Kumar and Debkumar Chakrabarti., 2013. Ergonomic Problems Prevalent in Handloom Units of North East India. International Journal of Scientific and Research Publications, ISSN 2250-3153.

[11] Sangeun Jin., Ryan McCulloch., Gary A. Mirka., Daniel Imbeau., Karine Aubry and Alain Delisle., 2012 Comparing the results of eight methods used to evaluate risk factors associated with musculoskeletal disorders. International Journal of Industrial Ergonomics 42, 478 488 .

[12] Sean Gallagher and William S. Marras., 2012 Tolerance of the lumbar spine to shear. Clinical Biomechanics 27, 973-978.

[13] Surface Vehicle Information Report Superseding J985 DEC2002.

[14] Sougata Karmakar,, Sanjog J and Thaneswer Patel., 2014. Digital Human Modeling and Simulation in Product and Workplace Design: Indian Scenario. International Journal of Engineering Research and Applications (IJERA) ISSN: 2248-9622.

[15] Troy Jones., Megan Strickfaden and Shrawan Kumar., 2005. Physical demands analysis of occupational tasks in neighborhood pubs Applied Ergonomics 36, 535-545 